\title{
EL GOBIERNO Y LAS LIBERTADES LA RUTA DEL LIBERALISMO CHILENO EN EL SIGLO XIX ${ }^{1}$
}

\author{
Iván Jaksic y Sol Serrano
}

En este ensayo se bosquejan los grandes hitos del pensamiento y la acción política liberal en Chile durante el siglo XIX. Los autores subrayan que el fuerte énfasis en la división de los poderes del Estado y la progresiva erosión de las fa-

IVÁN JAKSIC. Profesor titular asociado del Instituto de Historia de la Universidad Católica de Chile y Director del Programa de la Universidad de Stanford en América Latina. Ha ejercido cargos docentes y de investigación en las universidades de Berkeley, Wisconsin, Harvard, Oxford y Notre Dame. Su obra Andrés Bello: La Pasión por el Orden (2001), publicada también por Cambridge University Press, recibió el Premio Pensamiento de América del Instituto Pan Americano de Geografía e Historia. Fue nombrado Fellow de la Fundación Guggenheim el año 2002-2003. Su última obra Ven Conmigo a la España Lejana: Los Intelectuales Norteamericanos ante el Mundo Hispano, 1820-1880 (Fondo de Cultura Económica, 2007), fue publicada en inglés por Palgrave Macmillan.

Sol Serrano. Doctor en Historia, Universidad Católica de Chile; M.A., Yale University. Profesora de Historia de la Universidad Católica de Chile. Ha sido investigadora visitante en el Colegio de México, Saint Antony’s College, de la Universidad de Oxford, Erasmus Institute de la Universidad de Notre Dame y en la Universidad de París I, Sorbonne. Autora de numerosas publicaciones, entre ellas, de los libros Universidad y Nación. Chile en el Siglo XIX (Editorial Universitaria, 1994), Chile en el Siglo XX (varios autores) (Editorial Planeta). Su obra más reciente es Qué Hacer con Dios en la República: Política y Secularización en Chile (Fondo de Cultura Económica, 2008).

${ }^{1}$ Los autores agradecen los comentarios de Juan Luis Ossa Santa Cruz, Eduardo Posada-Carbo y J. Samuel Valenzuela. A este último agradecemos, en particular, tanto sus detalladas sugerencias como el permiso para utilizar su trabajo inédito "From Town Assemblies to Representative Democracy: The Contested Building of Electoral Institutions in post-Colonial Chile” (Universidad de Notre Dame, 2009).

Estudios Públicos, 118 (otoño 2010). 
cultades del Ejecutivo conllevó una ampliación de las libertades tradicionalmente asociadas con el liberalismo: los derechos individuales, la libertad de asociación, la libertad de imprenta, la ampliación del sufragio y del electorado, la libertad de enseñanza y la tolerancia religiosa. A su vez, se hace hincapié en lo que hay de liberal en el pensamiento y en la acción política conservadora. Así, se propone que existía un mayor consenso intelectual y político de lo que permite la historiografía en torno al debate público y a las reformas del sistema político. Finalmente, se destaca el papel que tuvo el conflicto religioso en perfilar los rasgos distintivos del liberalismo chileno.

Palabras clave: liberalismo; conservadurismo; conflicto religioso; reforma política; educación; Constitución de 1833.

Recibido: agosto 2009.

ـos principios fundamentales del liberalismo, y principalmente el de la protección del individuo frente a los abusos de la autoridad, tuvieron una rápida y duradera recepción en Chile desde que éste asumiera formas republicanas a partir de la independencia. Es decir que en la amplia gama de la agenda liberal internacional, Chile se sitúa en aquella parte del espectro que tiene que ver con la protección del individuo y de la sociedad respecto del poder despótico. Fue precisamente el abuso del poder, ya sea por parte de las autoridades realistas durante la Reconquista de 1814-1817, el gobierno dictatorial (aunque con algunos rasgos liberales) de Bernardo O’Higgins entre 1817 y 1823, o ciertas normativas de la Constitución de 1833, el que demostró una y otra vez la necesidad de imponer cortapisas al Ejecutivo mediante un sistema representativo en el que el Congreso tuviese poderes efectivos.

El ideario liberal tuvo éxito y fue compartido por la gran mayoría de los sectores políticos dadas las características del país: pequeño y homogéneo, sin grandes diferencias regionales, y en el que el Estado centralizador borbónico había propiciado la modesta prosperidad de una de las colonias más remotas del imperio. Por sobre todo, había afianzado una cultura jurídica, con la creación de la Universidad de San Felipe y el desempeño de los abogados a través de la audiencia. El Estado tenía prestigio, o al menos no había institución que tuviera mayor legitimidad. Y fue a través del Estado que se iniciaron las refor- 
mas que durante el siglo XIX fueron ampliando las libertades individuales e introduciendo un equilibrio de poderes de modo tal que el Ejecutivo no impusiera unilateralmente su poder. El liberalismo suministró los elementos conceptuales y las herramientas políticas, para que estas reformas tuvieran lugar en un prolongado período en donde, al menos en términos comparativos hispanoamericanos, predominó la continuidad más que la ruptura de la institucionalidad republicana.

Es así que el liberalismo chileno se caracteriza por tres elementos principales: 1) el consenso entre fuerzas políticas dispares y antagónicas en torno a la forma republicana de gobierno, en donde lo que estaba en pugna era la mayor o menor libertad de los individuos y la sociedad para definir los contenidos, fines y formas de la representación; 2) la búsqueda constante de equilibrio entre los poderes del Ejecutivo y los del Congreso, en la que terminó predominando este último, si bien con consecuencias inesperadas, luego de la instauración del período llamado "parlamentario" a fines del siglo XIX, y 3) el que todas las transformaciones de carácter liberal fueron logradas mediante reformas antes que revoluciones. El fracaso de los levantamientos armados de 1851 y 1859 en contra del régimen demostró que no había más camino que el político para la consecución de fines liberales. La oposición armada, de hecho, afianzó el poder del Ejecutivo, que privilegió el orden por sobre la expansión de las libertades durante el período denominado conservador, entre 1830 y 1860.

La historiografía chilena sobre el liberalismo es relativamente limitada, aparte de lo que Simon Collier, en un importante ensayo de 1977, denominó "la perspectiva Whig de la historia”, es decir, historias triunfalistas del papel que el "Estado Portaliano" jugó en la historia política e intelectual del país entre 1830 y 1891². Son escasos los estudios sobre el liberalismo tanto en sus aspectos filosóficos, como en aquellos aspectos programáticos que predominaron en el país. Con todo, importa mencionar los hitos historiográficos más importantes, como la obra de Ricardo Donoso, Las Ideas Políticas en Chile (1946), que contiene valiosas reflexiones en torno a los énfasis políticos del liberalismo chileno, y la obra del mismo Simon Collier, Chile: La Construcción de una República, 1830-1865 (2005), que representa no

2 Simon Collier, “The Historiography of the 'Portalian' Period (1830-1891) in Chile”, 1977, pp. 660-690. Algunas de las fuentes mencionadas por Collier serán comentadas más adelante en este artículo. 
sólo su última reflexión sobre la historia de Chile, sino que un esfuerzo por evaluar el rol de las ideas, y en particular del liberalismo, en el desarrollo y la cultura política de Chile ${ }^{3}$. En el presente ensayo, analizamos los logros, avances y carencias del pensamiento liberal a partir de tal historiografía, pero ubicándolo tanto en el marco de las ideas liberales clásicas, como en los ejes políticos en donde se produjeron los debates que desembocaron en una ampliación de las libertades, y en una nueva concepción tanto del gobierno como del espacio público.

\section{Los primeros pasos}

El proceso de la Independencia de Chile (1810-1830) tuvo al menos dos variables que pueden servir de ejes explicativos y en cierto sentido fundacionales de la historia política del siglo XIX: la lucha por la soberanía territorial —que con la Independencia devendría nacional- y la constitución de un gobierno legítimo. Ambas se vinculan estrechamente, pues la independencia de España implicaba construir una nueva forma de gobierno. Evidentemente no se plantearon de esa manera desde el inicio, pero estuvieron presentes desde la formación de una Junta de Gobierno en 1810 como respuesta a la crisis monárquica española. Su objetivo era convocar a elecciones de diputados de las provincias para que un Congreso definiera la forma de gobierno más apropiada para las nuevas circunstancias. Ese lenguaje y esos conceptos remitían a la tradición tanto como contenían los tiempos políticos del futuro, los del liberalismo.

\footnotetext{
${ }^{3}$ Nuestro ensayo no tiene la pretensión de hacer un examen historiográfico del liberalismo en Chile. Esto ya ha sido hecho en parte en las fuentes mencionadas y en Alfredo Jocelyn-Holt, "Liberalismo y Modernidad. Ideología y Simbolismo en el Chile Decimonónico: Un Marco Teórico”, en Ricardo Krebs y Cristián Gazmuri (eds.), La Revolución Francesa y Chile, 1990, pp. 303-333 y en La Independencia de Chile: Tradición, Modernización y Mito, 1992. Otras obras, como las de Ana María Stuven, Las Élites y la Construcción de Chile en las Polémicas Culturales y Políticas del Siglo XIX, 2000, y Manuel Vicuña, Un Juez en los Infiernos: Benjamín Vicuña Mackenna, 2009, sin ser sobre el liberalismo, tocan temas atingentes a éste. Obras recientes de Gabriel Salazar y de Julio Pinto cubren el período temprano desde una perspectiva social o política pero no se proponen abordar el liberalismo como filosofía o movimiento intelectual y político. Véase, de Gabriel Salazar, Construcción de Estado en Chile (1800-1837). Democracia de los "Pueblos". Militarismo Ciudadano. Golpismo Oligárquico, 2005, y de Julio Pinto Vallejos y Verónica Valdivia Ortiz de Zárate, ¿Chilenos Todos? La Construcción Social de la Nación (1810-1840), 2009.
} 
El primer gobierno nacional, el de Bernardo O’Higgins, se caracterizó por políticas de corte liberal (abolición de títulos nobiliarios, un cierto grado de libertad religiosa) y medidas dictatoriales que generaron suficiente oposición como para forzar su abdicación en 1823. En los siguientes años, de 1823 a 1830 se implementaron una serie de experimentos gubernamentales con rasgos federalistas, tales como la creación de asambleas provinciales con miembros electos en diferentes regiones del país. La expresión más notable del liberalismo del período fue la Constitución de 1828, en la que cupo un papel preponderante al liberal gaditano José Joaquín de Mora. Ella aseguraba derechos como la libertad, la seguridad, la propiedad, y la facultad de publicar opiniones sin censura previa (aunque sujeta a una ley de imprenta). Eliminaba el privilegio de los mayorazgos, limitaba las atribuciones del presidente, y entregaba el gobierno de las ocho provincias de la república a los intendentes propuestos al ejecutivo por asambleas autónomas ${ }^{4}$.

Los doce años que transcurrieron desde la independencia en 1818 hasta la reacción conservadora en 1830 aparecen confusos si se describen desde los cambios de gobierno y de las constituciones. Sin embargo, son coherentes analizados desde la perspectiva de la construcción de un régimen político liberal — soberanía popular, división de poderes, garantías individuales, igualdad ante la ley- que fuera territorialmente representativo a la vez que diera gobernabilidad ${ }^{5}$. En esos doce años la tensión entre las libertades, la representación y la gobernabilidad probaron hasta qué punto marcarían no sólo la fundación sino el desarrollo del sistema político chileno. Se desprende de esta afirmación que el liberalismo fue su sustento ideológico y el que hace inteligibles sus continuidades y sus cambios.

\section{La supremacía del gobierno}

El liberalismo como eje explicativo de la historia política chilena permite otorgar una mayor continuidad al período de la Independencia con el de la República Conservadora (1830-1860). La República Con-

${ }^{4}$ El texto de la Constitución se encuentra en Luis Valencia Avaria, Anales de la República de Chile, 2 tomos, 1986, I, pp. 150-171. Véase también Ricardo Donoso, Las Ideas Políticas en Chile, 1946, pp. 82-84.

${ }^{5}$ Sobre la década de 1820, véase Melchor Concha y Toro, Chile durante los Años de 1824 a 1828, 1862, obra que contiene abundante información documental. También, Simon Collier, Ideas and Politics of Chilean Independence, 1808-1833, 1967. 
servadora significó un repliegue de la ampliación de las libertades y de la representación en función del fortalecimiento del gobierno, y eso se llevó a cabo por la vía armada tras la derrota del gobierno liberal en la batalla de Lircay en abril de 1830. El régimen político que entonces se instauró, expresado en la Constitución de 1833, era fuertemente presidencialista, centralizado y con recursos legales para imponer el orden ${ }^{6}$. Sin embargo, era también un régimen constitucional, popular representativo, que establecía la separación de los poderes, la igualdad ante la ley y las garantías individuales. A pesar de que sus primeros dos mandatarios, Joaquín Prieto y Manuel Bulnes fueron militares, eran gobiernos civiles que mantuvieron al ejército neutralizado en base a la formación de una numerosa Guardia Nacional. Tal como lo concibieron sus principales políticos o ideólogos como Diego Portales, Mariano Egaña y Andrés Bello, el régimen diseñado en 1833 debía evolucionar hacia mayores libertades en la medida en que no pusiera en riesgo el orden social ni la estabilidad política. De aquí la famosa frase de Portales, a propósito de la ausencia de virtudes en el pueblo, "Cuando se hayan moralizado, venga el Gobierno completamente liberal, libre y lleno de ideales, donde tengan parte todos los ciudadanos"7.

En efecto, el presidente de la República controlaba los otros poderes del Estado y con ello dominaba la restringida arena política a través de los funcionarios locales y la Guardia Nacional. No obstante, al mismo tiempo el Congreso tenía atribuciones significativas para limitar el poder del gobierno, como la aprobación de la ley de presupuesto, el cuestionamiento de los ministros y la residencia de las fuerzas de tierra y mar. Además, nombraba a los jueces, pero no incidía directamente en la administración de justicia. El poder del gobierno estaba limitado por las garantías individuales establecidas en la Constitución (igualdad ante la ley, libertad de movimiento, inviolabilidad de las propiedades, derecho de petición y libertad de imprenta, entre otras), pero podían suspenderse fácilmente a través de las facultades extraordinarias que los gobiernos conservadores usaron durante un tercio de su período. Importa enfatizar

${ }^{6}$ Véase al respecto Antonio Huneeus Gana, La Constitución de 1833: Ensayo sobre Nuestra Historia Constitucional de un Siglo, 1933; Renato Cristi y Pablo RuizTagle, La República en Chile: Teoría y Práctica del Constitucionalismo Republicano, 2006. Desde una perspectiva comparada, Brian Loveman, The Constitution of Tyranny: Regimes of Exception in Spanish America, 1993, pp. 313-353.

${ }^{7}$ Diego Portales a José Manuel Cea, marzo (día no indicado) de 1822, en Carmen Fariña Vicuña, comp., Epistolario Diego Portales, 2 tomos, 2007, I, p. 8. 
este aspecto, puesto que el modelo contiene las semillas de su propia liberalización, en cuanto a que el Congreso tenía facultades reales de contrapeso y en cuanto se legitimaba el sistema de elecciones. Estas fueron limitadas a ciudadanos "activos", es decir, con un derecho a voto derivado de la propiedad o empleo, y del alfabetismo que incluía a guardias civiles de origen popular y a artesanos y en el cual se competía de manera crecientemente significativa ${ }^{8}$.

En lo que respecta a la religión, si bien las constituciones anteriores a la de 1833 declararon todas el carácter católico del Estado, ésta fue explícita en prohibir el culto público de cualquier otra religión, al mismo tiempo que era regalista y que reclamaba para su soberanía los derechos de patronato heredados de la monarquía. El gobierno conservador devolvió los bienes secuestrados a la Iglesia y llegó a un modus vivendi en los complejos problemas jurisdiccionales que el reclamo del patronato significaba para el gobierno eclesiástico cuando aquel no era reconocido por la Santa Sede. Tanto o más importante que aquello, la cúpula del gobierno y la cúpula eclesiástica eran igualmente "peluconas" - el sobrenombre que se les dio a los conservadores—, igualmente republicanas, igualmente temerosas de la anarquía y de las rebeliones populares. Sin embargo, el principio de legitimidad del sistema político se había secularizado, era jurídico y no religioso y si bien la unanimidad católica parecía resguardada con la catolicidad del Estado, la religión entraría a formar parte de los temas debatibles en el contexto de un espacio público embrionario.

El conservadurismo liberal, de matriz ilustrada, le otorgaba al conocimiento y a la educación un sentido transformador y utilitario que llevó al gobierno a consolidar el espacio de la República de las Letras y un debate político que encontró su cauce en la prensa y el parlamento. En este espacio la representación se discutía no sólo como un tema territorial sino como el origen de la expansión de las libertades en torno al cual se aglutinaron corrientes de opinión y finalmente se formaron los partidos políticos.

${ }^{8}$ La obligatoriedad del alfabetismo debía regir a partir del año 1841, por las disposiciones transitorias al artículo octavo de la Constitución de 1833. Sin embargo, el Congreso no quitó este derecho a quienes lo poseían con anterioridad. Los mejores estudios sobre la evolución del sufragio y del régimen de elecciones en Chile en el siglo XIX son los de J. Samuel Valenzuela, Democracia Vía Reforma: La Expansión del Sufragio en Chile, 1985, y "Building Aspects of Democracy: Electoral Practices in Nineteenth-Century Chile”, 1996, pp. 223-257. 


\section{La libertad en la República de las Letras}

Chile fue una de las últimas provincias del imperio español en América en tener una imprenta. Esta fue encargada a Estados Unidos por la Junta de Gobierno en 1811, e imprimió el primer periódico del país, La Aurora de Chile. La formación intelectual de los criollos había privilegiado la formación jurídica en derecho civil y canónico, y los estudios eclesiásticos. Con la fundación del Instituto Nacional en 1813 y la de la Universidad de Chile en 1842 se ampliaron los estudios hacia las ciencias naturales, las humanidades y las carreras profesionales. La circulación de libros importados fue más intensa, así como la impresión de publicaciones locales y la extensión de la prensa permitió una importante ampliación del debate ${ }^{9}$. En cierto sentido, la República de las Letras no antecede sino que es contemporánea de la formación del nuevo espacio público deliberante y por ello son inseparables.

A pesar de la revolución conservadora de 1829-1830, varias leyes liberales permanecieron vigentes, incluyendo, y muy especialmente, la Ley de Imprenta de 1828. Incluso durante un período amargamente denunciado como represivo, abundaron los periódicos y pasquines que atacaban las políticas del gobierno, o servían de canales de opinión para disidentes dentro del mismo gobierno. Las leyes de imprenta fueron aplicadas con rigor, aunque eso mismo significó que se realizaran juicios con dinámicas propias de tumultos callejeros y renovados ataques al gobierno ${ }^{10}$.

Durante el período más distendido del primer gobierno de Manuel Bulnes, entre 1841 y 1846, se observa un notable crecimiento no sólo de la cantidad de periódicos publicados, sino de la duración y circulación de estos medios ${ }^{11}$. El contenido también cambió, puesto

${ }^{9}$ La mejor fuente para apreciar la importación y circulación de libros y prensa periódica en el Chile decimonónico es Ramón Briseño, Estadística Bibliográfica de la Literatura Chilena, 1812-1876, 3 tomos, 1862-1879. Véase también José Toribio Medina, Biblioteca Chilena de Traductores (1820-1924), segunda edición corregida y aumentada 2007, y Bernardo Subercaseaux, Historia del Libro en Chile (Alma y Cuerpo), segunda edición, 2000.

${ }^{10}$ Raúl Silva Castro, Prensa y Periodismo en Chile, 1812-1956,1958; Gonzalo Piwonka Figueroa, Orígenes de la Libertad de Prensa en Chile, 1823-1830, 2000; Ricardo Donoso, “La Libertad de Imprenta”, en su Las Ideas Políticas en Chile, 1946, pp. 344-380.

${ }^{11}$ Iván Jaksic, “Sarmiento y la Prensa Chilena, 1841-1851”, 1991-1992, pp. 117-144. 
que hubo mayor cobertura de temas culturales y sociales que proporcionaron los primeros escenarios de debate público para una nueva generación de intelectuales, tanto del campo conservador como del liberal. Pero fueron los liberales como José Victorino Lastarria, y radicales como Francisco Bilbao, quienes lideraron los ataques más duros contra lo que consideraban los legados coloniales y contra el autoritarismo que identificaban con Portales. La expansión del ámbito público posibilitado por la mayor circulación de periódicos abrió un importante canal para la difusión de ideas liberales.

El documento que mejor retrata el mayor ascendiente y circulación de estas ideas es Bases de la Reforma, publicado en 1850 y redactado por José Victorino Lastarria y Federico Errázuriz. Se trató de un programa presentado ante el Congreso en agosto de 1849 y que se caracterizó, como el título lo indica, por el llamado a las "reformas" antes que a la transformación radical del sistema político. Resulta significativo que el primer proyecto de reforma fuese el de la libertad de imprenta, precisamente porque se vio en él un mecanismo efectivo para la difusión de las ideas liberales, en respuesta a la restrictiva ley de imprenta de 1846, que permitió al gobierno de Bulnes clausurar periódicos y exiliar a sus editores. También se exigían, entre otras reformas, la de la ley de elecciones; las restricciones al uso de las facultades extraordinarias y declaraciones de estado de sitio; la abolición de la degradante pena de azotes, y la reforma de la guardia cívica, "para hacerla más independiente i menos onerosa al pueblo”. A esto, en su mayoría proyectos de ley, se sumaban como metas la igualdad ante la ley, la libertad individual, la inviolabilidad de las propiedades, la instrucción primaria gratuita, y la protección de la industria. En suma, se trató del plan más elaborado y coherente de inspiración liberal en la primera mitad del siglo.

Cabe señalar que este programa no significaba un retorno al primer liberalismo chileno de la década de 1820, con sus propuestas federalistas y sus aboliciones abruptas de instituciones como el mayorazgo. El programa liberal de 1849 declaró no buscar "trastorno" alguno, como podrían suponerlo los sectores más conservadores. Por el contrario, prometió que no "pondrá en planta sus principios sino del modo más prudente, para no dañar”. Ni siquiera llamó a la derogación de la Constitución de 1833, sino que trató de explicarla en su contexto histórico: 
Nosotros que hemos mirado la Constitución de 33 como el código mejor calculado para los antecedentes i circunstancias en que se promulgó, por cuanto sólo por su medio podía regularizarse i fortificarse el poder del Estado, que entonces necesitaba de fuerza para mantener la tranquilidad pública, creemos que esa Constitución de 33 ha hecho ya su tiempo i que por tanto debe reformarse.

Para fines de la década de 1840, declaró este manifiesto, no existía ya justificación para mantener incólume una Constitución que pudo tener sentido cuando "el país anhelaba el orden i necesitaba un poder fuerte que le diese quietud i seguridad”. En el presente, argumentaban, la Constitución era un obstáculo para el desarrollo y progreso del país. "Mantener una organización política que fue creada para una época de anarquía, es lo mismo que confundir dos épocas mui diversas i negar que Chile se encuentra en estado de pedir más justicia i más libertad”. Sin las reformas propuestas, anunciaban, peligra la estabilidad del país. "Las reformas son las únicas que impiden las revoluciones", declaraban; "conservar lo existente con lijeras modificaciones es hacer necesaria la revolución”12.

La revolución de hecho estalló al año siguiente de esta publicación, aunque en gran medida debido a las vicisitudes de la sucesión presidencial, cuya candidatura recayó en la persona más identificada con el gobierno conservador: Manuel Montt. Luego de la Revolución de 1851, los liberales comprendieron que, además de un programa de reformas, eran necesarias las alianzas políticas, aunque fuese con los más detestados miembros del peluconismo pro-clerical. El historiador Raúl Silva Castro ha comentado respecto de la generación de Lastarria que "entre 1849 y 1852 calmaron su inquietud y optaron por el gobierno regular desechando la tentación de la fuerza"13.

\section{La ampliación de las libertades}

El conflicto político dominante dentro de la clase dirigente fue la liberalización del poder que la Constitución de 1833 y las prácticas políticas le daban al Presidente de la República. En una carta escrita en

\footnotetext{
${ }^{12}$ Las citas provienen de Bases de la reforma, 1850.

${ }^{13}$ José Victorino Lastarria, Diario Político, 1849-1852, 1968, p. 20. Sobre esta generación de liberales, véase Benjamín Vicuña Mackenna, Los Girondinos Chilenos,
} 1989. 
1849, refiriéndose al gobierno de Joaquín Prieto, José Victorino Lastarria recordó aquello que lo motivó a entrar muy prematuramente en la política: "Mi afición a los negocios públicos data de los primeros años de mi vida. Con todo el ardor de la niñez en mi corazón y con todas las teorías republicanas en mi cabeza, lo primero que vi en mi país, cuando empecé a fijarme en los hechos que entonces sucedían, fue un gobierno fuerte, exclusivo, un poder absoluto que castigaba con el destierro o con el cadalso a un partido arruinado, el cual invocaba en su defensa, una constitución liberal”14. Con estas palabras se definía quizás el énfasis más importante del liberalismo chileno antes de los debates en torno a los temas religiosos: el poder omnímodo de la presidencia. Surgieron entonces diversas formas de oposición: primero un grupo afín al ministro del Interior, Manuel Camilo Vial, quien al caer en desgracia política en 1849 pasó a la oposición, y que se identificaba confusamente con las ideas liberales. Más tarde, en 1850, jóvenes burgueses imbuidos del republicanismo francés organizaron La Sociedad de la Igualdad y en alianza con grupos de artesanos se opusieron con barricadas a la elección de Manuel Montt como presidente de la República. Al año siguiente, a liberales e "igualitarios” se sumó el general José María de la Cruz con las fuerzas militares de Concepción. La guerra civil de 1851 duró tres meses, enfrentó intereses y sentimientos opositores muy diversos, unos contra el autoritarismo y otros contra el centralismo y fue sofocada por el gobierno ${ }^{15}$. En gran medida, era la desconfianza en torno a la corrección de las elecciones la que precipitaba los conflictos de sucesión. En 1859 tendría que enfrentar otra guerra civil, esta vez liderada por las provincias mineras del norte.

El gobierno, como ha dicho Simon Collier, tuvo un triunfo militar pero una derrota política ${ }^{16}$. Entre una guerra civil y otra las fuerzas conservadoras de gobierno se habían dividido en torno al tema religioso dando origen a la formación de los partidos políticos. Un hecho aparentemente insignificante mostró los riesgos políticos del marco jurídico

${ }^{14}$ Carta de Lastarria a electores de Rancagua, 13 de abril de 1849, en Correspondencia entre Sarmiento y Lastarria, 1844-1888, 1954, p. 16.

${ }^{15}$ Benjamín Vicuña Mackenna, Historia de la Jornada del 20 de Abril de 1851. Una Batalla en las Calles de Santiago, 1878; Alberto Edwards, El Gobierno de Don Manuel Montt, 1851-1861, 1932.

${ }^{16}$ Simon Collier, "From Independence to the War of the Pacific", 1993, p. 9. 
que regía las relaciones entre Iglesia y Estado. En 1856, ante un conflicto jurisdiccional, un miembro subalterno del cabildo eclesiástico hizo uso del recurso de fuerza, lo que llevó a que la Corte Suprema invalidara una orden del Arzobispo y fallara su destierro por incumplimiento con el apoyo implícito del Presidente de la República, Manuel Montt. La “cuestión del sacristán” fue un punto de inflexión pues dividió el conservadurismo gobernante entre los regalistas que fueron llamados nacionales o montt-varistas y los ultramontanos que defendieron la independencia de la Iglesia y que formaron el Partido Conservador ${ }^{17}$. En la oposición, los ultramontanos hicieron alianza con los sectores liberales y participaron en contra de Montt en la revolución de 1859. Montt ya no pudo imponer a su propio candidato para el período siguiente y nombró a José Joaquín Pérez, político moderado que daba garantías de gobernabilidad a liberales y conservadores. Era el triunfo de la nueva alianza llamada Fusión Liberal-Conservadora. Los sectores más doctrinarios del liberalismo no aceptaron ese pacto y fundaron el Partido Radical.

$\mathrm{Al}$ iniciarse la década de 1860 los partidos ya estaban constituidos, aunque aún no se realizaban formalmente las convenciones de partidos, y las coaliciones se definieron en torno a la ampliación de las libertades. Las reformas constitucionales siguientes —el principal triunfo programático de la Fusión Liberal-Conservadora- empezaron a discutirse en 1870 y fueron aprobadas entre 1873 y 1874. Ellas tenían por objeto limitar el poder del Presidente de la República, asegurar las garantías constitucionales y reforzar la división de poderes ${ }^{18}$. Se prohibió la reelección presidencial, se limitaron las facultades extraordinarias y el estado de sitio, se declaró la incompatibilidad entre la calidad de parlamentario y funcionario, se facilitó la interpelación a los ministros de Estado, se incrementó la presencia de parlamentarios en la composición del Consejo de Estado, se rebajó el quórum legislativo para la reforma constitucional, y el senado quedó constituido por elección directa de las provincias, entre muchas otras. También se quiso asegu-

${ }^{17}$ Sobre el impacto político de este suceso, véase Sol Serrano, ¿Qué Hacer con Dios en la República? Política y Secularización en Chile, 1845-1885, 2008; Simon Collier, La Construcción de una República, 1830-1865. Política e Ideas, 2005; Timothy R. Scully, Los Partidos Políticos de Centro y la Evolución Política Chilena, 1992.

18 Jaime Eyzaguirre, Historia de las Instituciones Políticas y Sociales de Chile, 1970, p. 129; Julio Heise, Historia de Chile. El Período Parlamentario, 1974, p. 36; Agustín Edwards, Cuatro Presidentes de Chile, 1932, T. II, p. 155 y ss. 
rar las garantías constitucionales incorporando a la Constitución la libertad de reunión, de asociación y de enseñanza. Todas ellas erosionaban las bases del Estado conservador al cual se oponían liberales y católicos ultramontanos. Pero el conflicto entre autoritarismo presidencial y liberalización política se entrecruzaba crecientemente con el conflicto religioso en el que la alianza gobernante difería. En términos muy claros pero igualmente simplistas, el liberal Fanor Velasco describía así el panorama político de 1871: "[En Chile sólo había dos partidos] uno que trabaja por el progreso en todas las esferas de su actividad y por la libertad en todas sus manifestaciones, y otro que vive de los recuerdos del pasado, mirando con disgusto cuánto se aparta de las vías señaladas por una antigua tradición” ${ }^{\prime 9}$. Este último era el partido que llamaba ultramontano, que se apartaba del regalismo para defender la autonomía de la Iglesia. Con esto presagiaba el hecho que, en 1873, el Presidente Federico Errázuriz, liberal moderado elegido por la Fusión dos años antes, rompió con los conservadores; liberales y radicales formaron la Alianza Liberal que entró al gobierno con una agenda donde predominaba la secularización del Estado. Como acentuó el mismo Velasco: "Se ha creído que en nuestro país el ultramontanismo es una planta exótica. Equivocación profunda, porque desde que los sentimientos religiosos han podido explotarse en beneficio de mundanos intereses, en todas partes existe un ultramontanismo militante. Este ultramontanismo se manifiesta donde quiera que haya una creencia exclusivista y donde quiera que esta creencia cuente con el apoyo del Estado"20.

Una versión más moderada del liberalismo chileno es la proporcionada por Isidoro Errázuriz en Historia de la Administración Errázuriz (1877), que puede considerarse una historia Whig en la que el liberalismo se abría paso triunfalmente, aun cuando la obra estaba escrita en plenas batallas por la expansión de las libertades en el Congreso. Para Errázuriz, el liberalismo chileno comenzó con la abdicación de O’Higgins y más específicamente con la Constitución de 1823, cuyas virtudes principales residieron en dar al Congreso poderes reales de gobierno y en establecer las garantías individuales. Aunque reconocía defectos, la Constitución "descansaba sobre excelente base liberal y democrática” e incluía "un sistema completo y sólido de garantías para

\footnotetext{
${ }^{19}$ Fanor Velasco, La Idea Liberal y la Idea Ultramontana, 1871, p. 5.

${ }^{20}$ Ibid., p. 16.
} 
el derecho individual”21. El entonces Jefe de Estado Ramón Freire, sin embargo, "jamás pudo vivir en armonía con el cuerpo legislativo”, lo que desde su perspectiva le restaba autoridad como fundador del liberalismo chileno. "A pesar de habernos dado la República, estaba lejos de comprender en ella más que el nombre"22. Sin embargo, la Constitución misma tenía un defecto fundamental puesto que "suponía en los ciudadanos la conciencia profunda del derecho, el hábito de ejercerlo regularmente y de someterse a los deberes trazados por la lei”23. Tanto el federalismo de esos años como la legislación anticlerical del período 1824-25 exacerbaron las tensiones en un período de alta vulnerabilidad política.

El primer liberalismo chileno, así, condujo a una "reacción oligárquica” que retrasó por medio siglo lo logrado en 1823, es decir, la independencia del congreso y de las elecciones. Con Portales, "ya no se reputa como el fin primordial del Estado el establecimiento de instituciones democráticas y liberales, a favor de las cuales puedan consolidarse el respeto y la práctica del derecho... Ahora se pretende sacrificar todo lo demás al mantenimiento del orden”24. El período portaliano significó entonces "la abyección de los Congresos, la postración del espíritu público, el entronizamiento legal del absolutismo y la pérdida de las libertades”25. El principio de autoridad pasó a ser el eje de la política chilena, principio "que no es sino el sometimiento ciego de la Nación a la voluntad del Jefe del Ejecutivo"26. El gobierno de Manuel Bulnes significó un período en donde pudo abrirse paso el liberalismo, pero ahora con un sello reformista que enfatizaba políticas prácticas, como la abolición de los monopolios o la reforma de las leyes. Luego del primer liberalismo, o "pipiolismo" desacreditado, se funda alrededor de 1845 un liberalismo de "nueva escuela"27. Este se manifestó primordialmente a través de la prensa, pero ya para 1849 se puede hablar con seguridad de un "segundo partido liberal”: Durante el segundo período de Bulnes, "el espíritu nacional había experimentado una alteración notable; la libertad había dejado de ser una amenaza y un espectro

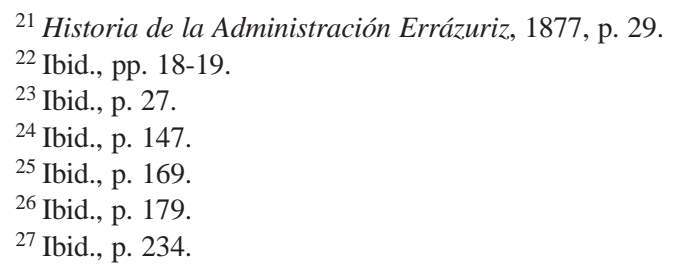


aterrador; en 1849 era una fuerza, con la cual los gobiernos podían y debían contar para defenderse, y las oposiciones para atacar"28.

Errázuriz detectó también un cambio fundamental en el bando conservador, que observó en la oposición al gabinete de Manuel Camilo Vial y en las elecciones de 1849: "el espectáculo del peluconismo amparándose en la libertad y sirviéndose de ella con tino, con discreción y con terrible eficacia, no podía menos que producir inmensa sensación. El autoritarismo empezaba a correr peligro de ser devorado por su propia prole"29. Si bien esto no debe entenderse literalmente, es claro que el sector conservador se había dividido y que los valores de competencia electoral y de debate público habían penetrado profundamente en el mundo político ${ }^{30}$.

En este contexto, se puede considerar la trayectoria intelectual y política de José Victorino Lastarria, quien confirmó la transformación de la cultura política chilena esbozada por Isidoro Errázuriz, pero con un sello más radical y sirviendo de puente hacia un liberalismo más positivista influido por el pensamiento de Augusto Comte. Inicialmente formado en el Liceo de Chile regentado por José Joaquín de Mora, Lastarria absorbió muy tempranamente el pensamiento de Bentham, el que luego difundió mediante su propia enseñanza en el Colegio de Romo en las décadas de 1830 y 1840, y en cuyo curso de legislación incluía también a Montesquieu y Constant. Estos tres pensadores, como testimonia en su Recuerdos Literarios, se encontraban disponibles en las librerías de Santiago ${ }^{31}$.

Muy en la línea de Isidoro Errázuriz a propósito del "nuevo liberalismo”, Lastarria señaló que a partir de 1842, cuando redactaba las páginas de El Semanario, "hemos procurado esparcir ideas liberales, pero exentas del rigor de los sistemas i de la exageración que suele hacerlas peligrosas; hemos querido mostrarlas aplicadas a la práctica, en vez de presentarlas en forma de teoría general y absoluta"32. Ya en el Congreso en 1849, y con Federico Errázuriz, había explicitado detalladamente la plataforma liberal que lo inspiraba en Bases de la Reforma.

\footnotetext{
${ }^{28}$ Ibid., p. 331.

${ }^{29}$ Ibid., p. 294.

${ }^{30}$ Un cuadro sobre la intensa competencia electoral del período se encuentra en Valenzuela, "From Town Assemblies”, p. 58.

${ }^{31}$ Lastarria, Recuerdos Literarios: Datos para la Historia Literaria de la América Española i del Progreso Intelectual de Chile, $2^{\text {a }}$ ed., 1885, p. 32.

${ }^{32}$ Ibid., p. 174.
} 
El eje fundamental del pensamiento liberal de Lastarria radicó en las libertades, principalmente en los aspectos políticos y religiosos, y específicamente la libertad y seguridad individual frente a los mecanismos autoritarios, como los regímenes de excepción permitidos por la Constitución de 1833. Pero su encuentro con Comte en la década de 1860 le llevó a enfatizar el "progreso" como la necesidad fundamental para el desarrollo democrático ${ }^{33}$. Haciendo una lectura retrospectiva de su propia trayectoria, señaló que ya poseía una convicción al respecto a fines de la década de 1840, cuando descubrió que era imposible crear "un verdadero partido liberal, sin difundir i afirmar la doctrina democrática" 34 . Sin ella, no podría haber progreso en el desarrollo político e intelectual del país. El contexto político era importante, en el sentido que tal doctrina es la que diferenciaría a los verdaderos liberales de los pelucones oportunistas que se habían sumado al gobierno de Bulnes para controlar las reformas, y que se denominaban "liberales moderados”. Lastarria entendía que aquella alianza no podría continuar por mucho tiempo, y de hecho se quebraría en torno al conflicto religioso.

Cabe mencionar que Lastarria no representa el único o principal baluarte del pensamiento liberal chileno, aunque esa era ciertamente la intención de su obra autobiográfica Recuerdos Literarios, es decir, establecerlo mediante una caracterización de su maestro Andrés Bello como un conservador extremo. Sin embargo, fue Bello quien introdujo, principalmente en el senado, una serie de políticas liberales en varias áreas como la codificación civil, el derecho privado internacional, las políticas de fomento (prelación de créditos, población de los puertos menores de la república, territorios abandonados por el mar), la abolición del fuero para los militares, consejeros de estado y ministros de despacho. Aunque sostuvo el catolicismo como religión de la república, abogó en la Cámara por la facultad de los extranjeros no católicos para radicarse en el país y adquirir derechos civiles ${ }^{35}$. Sin embargo, fue precisamente en torno al tema religioso que se produjo una escisión tanto en el liberalismo como en el campo conservador.

${ }^{33}$ Sobre el pensamiento político de Lastarria, véase Alejandro Fuenzalida Grandón, Lastarria i su Tiempo, 2 tomos, 1893; Alamiro de Ávila Martel, Antonia Rebolledo Hernández, Luz María Fuchslocher Arancibia, Javier Barrientos Grandón, Norman P. Sacks y Luis Oyarzún, Estudios sobre José Victorino Lastarria, 1988, y Bernardo Subercaseaux, Cultura y Sociedad Liberal en el Siglo XIX (Lastarria, Ideología y Literatura), 1981.

${ }^{34}$ Lastarria, Recuerdos Literarios, 1885, p. 210.

${ }^{35}$ Andrés Bello, Labor en el Senado de Chile (Discursos y Escritos), tomo XX, 1981; Iván Jaksic, Andrés Bello: La Pasión por el Orden, 2010. 


\section{El liberalismo regalista}

El regalismo - la protección y control del Estado en ciertas materias eclesiásticas - fue una corriente de continuidad entre la monarquía borbónica y el liberalismo republicano no sólo en las cúpulas políticas laicas sino entre variados sectores del clero. Las experiencias europeas, especialmente la francesa, mostraban cuán violento podía ser un conflicto entre ambos poderes y la necesidad de llegar a acuerdos negociados a través de concordatos. El papel de Roma y del Papa adquiría mayor relevancia a la vez que la posterior desintegración de los Estados Pontificios y las luchas contra el liberalismo habían dibujado con mayor precisión los contornos del ultramontanismo, es decir, de la disciplina de la Iglesia en torno al magisterio romano. Hacia mediados de siglo, el regalismo era la doctrina imperante en el Estado chileno y tenía muchas formas de expresión en el clero. El proceso por medio del cual el regalismo eclesiástico se transformó en ultramontanismo es de suyo complejo, pero es crucial para estudiar el liberalismo. El hito más expresivo fue la "cuestión del sacristán”, ya mencionada, donde el regalismo dentro del clero se asoció con el regalismo estatal. La Iglesia sintió amenazada su libertad y descansó en el Partido Conservador como en un brazo político para la defensa de su independencia ${ }^{36}$. Así, los conservadores tuvieron una doble bandera en contra del gobierno: el presidencialismo y el regalismo. Las distintas vertientes liberales, por su parte, también eran regalistas y por ello no propiciaban la separación de la Iglesia y del Estado sino el que éste pudiera seguir ejerciendo el patronato. Eran pocos, algunos radicales, los que defendían directamente la separación de ambos poderes.

El debate de las reformas constitucionales en la década de 1860 se inició artículo por artículo, por lo que pronto se llegó al quinto que establecía el carácter católico del Estado con exclusión del ejercicio público de cualquiera otra religión. En dicha ocasión, el debate no giró en torno a la separación sino que a la manera de garantizar el pluralismo religioso, es decir, el derecho a profesar libremente una religión. Tan regalista era la mayoría de la clase política que no se reformó la constitución ni se decretó la libertad de culto sino que se promulgó una ley interpretativa del artículo quinto por medio de la cual los disidentes

${ }^{36}$ J. Samuel Valenzuela y Érika Maza Valenzuela, “The Politics of Religion in a Catholic Country: Republican Democracy, Social Cristianismo, and the Conservative Party in Chile, 1850-1925”, 2000, pp. 188-223. 
podían profesar su culto y educar a sus hijos en su religión en lugares privados. Fue una ley de tolerancia religiosa (1865) la que autorizó la libertad de los disidentes pero mantuvo la catolicidad del Estado. La bandera de los gobiernos liberales posteriores fue la laicización del Estado bajo una argumentación ideológica que apelaba a la consolidación de la soberanía jurídica de la nación, esto es, que no hubiera otra fuente de derecho como garantía de la igualdad ante la ley. La Iglesia era una institución con fueros y privilegios, el derecho canónico regulaba el matrimonio de acuerdo al Código Civil, el mismo que le había otorgado soberanía en materias del culto. En la amplia familia del pensamiento político liberal, en materias religiosas el chileno estaba inspirado más por la defensa igualitaria del derecho público que por la defensa de los derechos individuales como límite al poder del Estado. Existe en la vida política del período una cierta distinción entre el énfasis que algunos sitúan en el liberalismo regalista que asegura la igualdad garantizada por el Estado, y el liberalismo pluralista que enfatiza la libertad del individuo. No son dos corrientes químicamente puras sino, al contrario, híbridas, entremezcladas en el discurso y en la misma legislación.

Esta diferencia se hizo evidente en esa agitada primera mitad de la década de 1870, con el paso de los conservadores a la oposición, cuando un grupo de parlamentarios sin el patrocinio del gobierno presentó un proyecto de reforma constitucional para suprimir el artículo quinto, sobre la confesionalidad del Estado, pero que mantenía el patronato. Ello se expresó muy concretamente en la discusión en el Congreso de la Ley Orgánica de Tribunales y el Proyecto de Código Penal en 1874 y 1875. En el primero se eliminaba el fuero eclesiástico y en el segundo se tipificaban delitos eclesiásticos derivados del patronato, lo que llevó a la jerarquía a excomulgar a los parlamentarios que los aprobaran. En el proceso de construcción de la igualdad ante el derecho, la catolicidad del Estado era una fuente de conflictos por el privilegio que ello entrañaba para la Iglesia. Pero el problema también existía en sentido inverso: la Iglesia pagaba un precio muy alto a través del patronato y el exequátur, que era a su vez una forma de discriminación en la igualdad jurídica. El fuero eclesiástico y los delitos eclesiásticos muestran las dos caras ${ }^{37}$.

37 "Edicto Pastoral de los Obispos sobre Libertad de Enseñanza Católica, Matrimonio Civil i Separación entre la Iglesia y el Estado”, 17 de noviembre de 1874, Boletín Eclesiástico, T.V, pp. 987-998; "Reclamación del Episcopado contra el proyecto de Código de organización de Tribunales”, 8 de junio de 1875, Boletín Eclesiástico, T. VI, pp. 62-75. 
El alcance de la soberanía fue uno de los principales temas del debate. Los conservadores sostenían que el Estado chileno debía pedir autorización a la Santa Sede para cambiar cualquier materia propia de la Iglesia, invocando el artículo quinto de la Constitución, cuestión que provocaba las iras liberales: "Este país que se cree soberano", reclamaba el diputado y futuro presidente Domingo Santa María, "ha ido a postrar su frente ante la Curia Romana... El Estado es el que tiene la soberanía, y por consiguiente la jurisdicción y el ejercicio de ella, es el único que puede delegarla y confiarla en todo o parte a estos o a aquellos tribunales creados por la ley dictada por el mismo Estado"38. Directamente ligado con la soberanía estaban las excepciones a la igualdad jurídica que significaban los fueros tanto eclesiástico como militar. El ministro de Justicia José María Barceló señalaba que "no hay ni puede haber institución que reclame como inherentes a ella derechos que son propios de la nación o del poder público que ella establece... El fuero eclesiástico es un privilegio y todo privilegio es odioso. Los privilegiados mismos tienen que aceptar odiosidades y prevenciones que les traen más molestias que las ventajas del privilegio"39. La otra cara del fuero - el costo del privilegio - eran los delitos eclesiásticos que sancionaban el incumplimiento de los deberes que los sacerdotes tenían hacia el Estado en cumplimiento del patronato. En octubre de 1873 el Presidente Errázuriz envió al Congreso el proyecto de Código Penal, elaborado largamente por una comisión especial, uno de cuyos artículos establecía que el "eclesiástico que en el ejercicio de sus funciones incitare directamente a la desobediencia de una ley, decreto o sentencia de autoridad competente será castigado con la pena de relegación menor”. También establecía la pena para quienes no respetaran el exequátur. El ministro del Interior Eulogio Altamirano insistió que los delitos allí tipificados provenían del carácter de empleados públicos que tenían los sacerdotes y defendió con dureza su competencia: "Porque sostenemos la ley que hemos jurado respetar, porque sostenemos que no hay nada que esté sobre la soberanía de la nación; porque declara-

${ }^{38}$ Sesiones del Congreso Nacional (SCN), 1874, Diputados, 3 de septiembre de 1874, p. 12.

${ }^{39}$ Ibid., p. 15. Barceló parece haber tomado el dictum de Sièyes en Essai sur les privilèges (1788) a propósito de la odiosidad de los privilegios para todo tipo de asociación política. La expresión también recuerda el comentario del Conde de Campomanes en el Tratado de la Regalía de Amortización (1765): “todo privilegio, es odioso”. 
mos francamente que en todo caso de conflicto entre la ley religiosa y la ley civil, sostendremos con energía la ley civil, se nos amenaza con la excomunión [...] Los señores senadores van a decirnos si el Concilio está sobre el Congreso de Chile" ${ }^{\text {40 }}$.

Los conservadores en ésta y en varias otras discusiones negaron estar defendiendo derechos corporativos sino las libertades individuales que garantizaba la Constitución. El conservador Enrique Tocornal sostuvo que el Código era una persecución a la Iglesia pues les negaba a los sacerdotes derechos propios de todo ciudadano: "Cualquier habitante de la república tendrá derecho de publicar sus opiniones sin más responsabilidad que la que impone la ley de imprenta, pero no si es sacerdote católico, porque se le somete a penas severísimas y excepcionales. Todo ciudadano goza del derecho de censurar las leyes [...] de fundar clubs, asociaciones, diarios y todo género de publicaciones para promover la reforma de la constitución...”. Pero los sacerdotes no podían emitir opiniones en cumplimiento de su deber, tenían menos derechos que los otorgados por la ley común siendo unos "parias en su propia patria"41. Finalmente el Senado suprimió estas disposiciones en buena medida porque ya se había aprobado la abolición del fuero eclesiástico ${ }^{42}$.

Las leyes laicas de la década de 1880, la de registro y matrimonio civil así como la de secularización de los cementerios permiten comprender el paso de un liberalismo regalista a un liberalismo pluralista. O dicho de otra forma, del énfasis puesto en la soberanía del Estado al de la defensa de los derechos de los individuos.

\section{Los derechos del individuo}

Los conflictos entre la Iglesia y el Estado llegaron a su punto máximo de tensión en 1878, cuando el gobierno propuso para la sucesión arzobispal a un connotado sacerdote regalista y con simpatías por los liberales. No sólo se opuso la curia local sino que también la Santa Sede. Cuando esa guerra diplomática, jurídica y política comenzaba, una guerra verdadera enfrentó a Chile con sus vecinos de Perú y

${ }^{40}$ Citado por Agustín Edwards, Cuatro Presidentes de Chile, 1932, p. 254.

${ }^{41}$ SCN, Diputados, 7 de octubre de 1874.

${ }^{42}$ Manuel de Rivacoba y Rivacoba, Código Penal de la República de Chile y Actas de las Sesiones de la Comisión Redactora, 1974. 
Bolivia. La Guerra del Pacífico significó una tregua en el conflicto religioso hasta que en 1881 hubo elecciones presidenciales y asumió como presidente el liberal Domingo Santa María, quien, junto con terminar la guerra, disciplinó a sus díscolas huestes liberales en torno a las "cuestiones teológicas".

Tal como en el caso del culto, la catolicidad del Estado planteaba el problema de los derechos de los disidentes en relación a la sepultura y el matrimonio. Ello se había enfrentado pragmáticamente cuando casos escandalosos habían obligado a una solución de tipo jurídico. Los protestantes tenían sus propios cementerios en Valparaíso y en Santiago (en un terreno aledaño al Cementerio General). En 1844 una ley —que más tarde pasó a formar parte del Código Civil— le otorgó valor legal al matrimonio entre disidentes en el cual el sacerdote católico actuaba sólo como ministro de fe. Pero sintomáticamente en el último tercio del siglo el problema ya no era con los disidentes, sino con los agnósticos y ateos. ¿Qué sucedía, entonces, con alguien que no era protestante ni católico? ¿Qué pasaba cuando un agnóstico quería casarse? ¿Qué pasaba a la hora del entierro cuando todos los cementerios eran benditos y de acuerdo con el Código Civil, los asuntos destinados al culto se regían por el derecho canónico? Eso no estaba resuelto ${ }^{43}$. En 1872, el gobierno envió una circular interpretativa de la ley de matrimonio de disidentes que mandaba a los párrocos inscribir a los no católicos, sin preguntar si tenían religión. Respecto de los cementerios, en 1871 se dictó un decreto que asignaba un espacio separado para aquellos cuya sepultura en terreno bendito estuviera negada por el derecho canónico. Pero sucedió más tarde que un joven suicida fue enterrado en la tumba de su padre que estaba en terreno bendito. Así, se sucedían los casos que ponían a prueba la igualdad ante la ley de los que no eran católicos o no estaban en regla con el derecho canónico. Es cierto que eran una minoría que podía contarse caso a caso, como lo reclamaron los conservadores y la Iglesia, pero doctrinaria y jurídicamente el problema estaba igualmente planteado. ¿Cómo se construía una sociedad plural en un Estado católico? José Manuel Balmaceda, el ministro del Interior que defendió las leyes laicas respondía: "En el siglo en que vivimos, el exclusivismo es una palabra muerta,

${ }^{43}$ Eyzaguirre, Historia..., 1970, p. 149 y Ricardo Donoso, Las Ideas Políticas en Chile, 1946, pp. 233-286. 
que los hechos destrozan a cada hora. Ya no existe en pueblo alguno la perfecta unidad religiosa y es por lo mismo imposible que haya ningún pueblo que pueda consagrar en sus códigos o en sus leyes, principios de intolerancia, absorciones del poder público por la autoridad de la Iglesia, que hacen imposible el acuerdo de las potestades civil y eclesiástica, o que las arrastran a una conflagración constante" ${ }^{44}$. En 1882 se discutió en el Congreso la secularización de los cementerios. La reacción católica fue defender su derecho a tener cementerios particulares. Fue en este punto donde el debate adquirió un giro inesperado premonitorio de los conflictos políticos que vendrían y que enfrentaba a las dos vertientes liberales mencionadas anteriormente. El gobierno y la mayoría liberal se opusieron a la autorización de cementerios particulares desde el supuesto de que sólo la igualdad de propiedad (la pública) aseguraría la igualdad de la no exclusión, mientras otros consideraban que el Estado no debía coartar los derechos de las personas. Fue un connotado senador radical, el héroe de la reciente Guerra del Pacífico José Francisco Vergara, quien propuso formalmente una indicación para que la ley incorporara la libertad para fundar cementerios particulares y ganó por un voto ${ }^{45}$. El proyecto tuvo que volver a la Cámara donde se enfrentaron los liberales gobiernistas con radicales y liberales que cuestionaban los fuertes poderes del gobierno. Los primeros defendieron el derecho de las familias de permanecer unidos en la muerte. "Se trata de que al lado de Perico abuelo, que era católico, se pueda enterrar a Perico hijo, que no cree en la infalibilidad del Papa, y al lado de éste, Perico nieto, que apenas es deísta, y a Perico bisnieto que no sabe nada de creencias y que tal vez lo llamen enemigo de Dios"46. Con menos ironía, la mayoría liberal defendió el sentimiento de la unidad familiar. Pero como señaló Augusto Orrego Luco, también liberal, lo que estaba en juego era una "doctrina igualitaria” contra la libertad del individuo ${ }^{47}$. La discusión fue extremadamente larga y mientras los liberales de gobierno acusaban a sus camaradas de haberse transformado en un "ala derecha" aliada con los conservadores, los otros reclamaban que la libertad de conciencia era un derecho tan válido para los libre pensadores como para los católicos. En la Cámara la autorización a los

\footnotetext{
${ }^{44}$ SCN, Senado, 26 de diciembre de 1883, p. 356.

${ }^{45}$ SCN, Senado, 22 de junio de 1883, p. 108.

${ }^{46}$ SCN, Diputados, 30 de junio de 1883, p. 143.

${ }^{47}$ SCN, Diputados, 3 de julio de 1883, p. 160.
} 
cementerios particulares perdió estrepitosamente mientras en el Senado casi empató. Ello indica que había un cuarto de los diputados y una mitad de los senadores que estaba haciendo el giro no sólo contra el excesivo poder del gobierno sino del Estado. En los años por venir esa fracción del liberalismo iría creciendo en forma casi proporcional a la afirmación del Presidente Balmaceda de la autoridad de su cargo. A ellos se sumaron los conservadores que coincidían con el credo liberal de restringir el poder del Estado sobre los individuos. El liberalismo en un amplio sentido — que incluía a los conservadores - fue mayoritario en su oposición a Balmaceda, lo que derivó en el sangriento enfrentamiento entre los constitucionalistas y los congresistas. Aunque la Guerra Civil de 1891 tuvo varias causas, incluyendo la cuestión electoral, representación y gobernabilidad se volvieron a enfrentar en esa fecha para dirimir el espacio del gobierno y el de las libertades ${ }^{48}$.

\section{La libertad de enseñanza}

A lo largo del siglo XIX, la Iglesia fue perdiendo gradualmente el control de las instituciones educacionales públicas. Tenía sus propios establecimientos de educación secundaria, entre los cuales los más importantes en Santiago eran el Seminario, el Colegio de los Sagrados Corazones (1849) y el Colegio San Ignacio (1856). El Seminario era financiado por el presupuesto público y los otros eran enteramente privados. Pero todos ellos debían regirse por los programas del Instituto Nacional, plantel que validaba los exámenes anuales que habilitaban para dar el examen de bachillerato e ingresar a la Universidad. El Estado no fijaba el currículum como tal, pues no tenía atribuciones legales para ello, sino que regulaba administrativamente el acceso a las profesiones. Esta regulación se hizo más conflictiva en la medida en que el Estado se laicizaba y la Iglesia la sentía como una forma de control ideológico a su propia enseñanza.

En 1871 asumió como presidente Federico Errázuriz apoyado por la fusión liberal-conservadora. La negociación con los conservadores resultó en que se nombrara como ministro de Justicia, Culto e Instrucción Pública a Abdón Cifuentes, una de las principales figuras

\footnotetext{
${ }^{48}$ Sobre la reforma electoral de 1890, véase Samuel Valenzuela, "La Ley Electoral de 1890 y la Democratización del Régimen Político Chileno”, 1998, pp. 265-296.
} 
del ultramontanismo, con el mandato de decretar la libertad de exámenes. Así lo hizo en enero de 1872 en una de las medidas más polémicas de la época. Se rebelaron los alumnos del Instituto que hicieron múltiples manifestaciones callejeras y asaltaron la casa del ministro; el rector del Instituto, el historiador liberal Diego Barros Arana, fue suspendido de su cargo; los parlamentarios liberales interpelaron al ministro, quien finalmente salió del gabinete al año siguiente, rompiéndose la coalición gobernante y dando paso a la formación de la Alianza Liberal.

Los conservadores, así como la jerarquía eclesiástica, defendieron la libertad de enseñanza como un derecho natural de los padres de familia y un derecho político de todo ciudadano ${ }^{49}$. Algunos no sólo se opusieron al rol regulatorio del Estado, sino a la existencia misma de la educación pública. El diputado conservador Zorobabel Rodríguez, en una posición más bien solitaria pero altamente provocativa, sostuvo, citando a Adam Smith, que el Estado sólo debía otorgar educación primaria y que la educación secundaria y superior eran un atentado contra el libre mercado, contra la libertad individual y una mala inversión de los dineros públicos, pues era una contribución que los pobres pagaban para que se educaran los ricos ${ }^{50}$.

Los liberales, por su parte, defendieron el rol histórico que había jugado el Estado Docente en su calidad de regulador. Pero lo más interesante del debate fue que por primera vez se hizo una defensa del rol del Estado como constructor de la igualdad positiva de los ciudadanos. El principal exponente de esta visión, el educador y político Miguel Luis Amunátegui, sostuvo que suprimir la educación pública era un plan aristocrático que contrariaba el principio de igualdad ante la ley y discriminaba en contra de los pobres: "Si no se fundan y mantienen escuelas y colegios con fondos públicos provenientes de contribuciones generales o locales, la sociedad queda precisamente dividida en dos clases rivales: la de la gente instruida y la de la gente ignorante; la de los hombres de la civilización y la de los hombres de la barbarie, colocados frente a frente, lado a lado, en actitud amenazante sin que casi nunca sea posible a los individuos de la segunda pasar a la categoría de los de

49 "Memoria del Ministro de Justicia, Culto e Instrucción Pública”, Anales de la Universidad de Chile, 1872, tomo 40, p. 185. Ricardo Krebs, Catolicismo y Laicismo..., 1981, capítulo "El Pensamiento de la Iglesia frente a la Laicización del Estado en Chile 1875-1885”; Abdón Cifuentes, Memorias, T. II, 1936, capítulo XVII, pp. 5-27.

${ }^{50}$ SCN, Diputados, 1873, p. 299. 
la primera, por falta de recursos, aunque tenga voluntad para ello"51. El carácter democratizador de la educación se constituyó entonces en la identidad de la educación pública y ya no la formación del hombre público, virtuoso e ilustrado, como en el período inmediatamente anterior.

Esta vez fueron los conservadores católicos los que asumieron la posición de la defensa de los derechos del individuo en contra del Estado. Los liberales en este campo mantuvieron una posición común en defensa del Estado docente que representaba para ellos la garantía de la libertad de pensamiento, la garantía de una educación uniforme de la clase dirigente y la garantía de la meritocracia. Allí se disputaba la formación de las elites, pues el conflicto no se dio en la instrucción primaria sino en la secundaria a la cual en el siglo XIX sólo accedía una pequeña parte de la población. Pero el conflicto, al contrario del caso ya visto de los cementerios, no consistía en la prohibición de la educación privada sino en su control a través de la reglamentación. "Nadie ignora que en Chile y en todas partes, el que es dueño de los exámenes es dueño de la enseñanza y árbitro de la cultura nacional”, señalaba Valentín Letelier, uno de los más connotados educadores positivistas de fines de siglo y rector de la Universidad de Chile ${ }^{52}$. Si bien los colegios católicos adquirieron más autonomía en los exámenes anuales, el examen para el bachillerato fue una herramienta que no cejó hasta avanzado el siglo XX y que continuó operando en la educación superior cuando el catolicismo ultramontano y la jerarquía eclesiástica fundaron la Universidad Católica en 1888. La posición asumida por los conservadores respecto de la defensa de la educación privada fue una bandera universal del catolicismo contra el Estado liberal. Los conservadores fueron los más críticos a la expansión del Estado y los más sensibles a la definición de sus límites, mientras los liberales le dieron al Estado un rol civilizador y democratizador que los llevó a defender sus prerrogativas. Los conservadores perdieron esa batalla lo cual los llevó a consolidar la educación católica dentro de la educación particular ${ }^{53}$.

La relación entre libertad y educación, sin embargo, no se limitó a la libertad de enseñanza. La educación fue considerada por la elite

\footnotetext{
${ }^{51}$ Anales de la Universidad de Chile, T. 42 (1873), p. 91.

52 Valentín Letelier, La Lucha por la Cultura..., 1895, p. 125; Iván Jaksic, Academic Rebels in Chile, 1989, pp. 49-56.

53 Juan Luis Ossa Santa Cruz, "El Estado y los Particulares en la Educación Chilena, 1888-1920”, 2007, pp. 23-96.
} 
política del siglo XIX como un elemento civilizador de las costumbres, requisito del individuo industrioso, pero principalmente como la vía por excelencia de la formación del ciudadano. Ello era evidente en la educación clásica de la juventud donde la inspiración republicana de la virtud pública formaba al ciudadano conductor de la nación. Sin embargo, también inspiró, junto al utilitarismo, la expansión de la educación primaria que es donde residía la verdadera novedad liberal. La escuela popular, como institución, era prácticamente inexistente en el Chile colonial y, si bien estuvo en el ideario del período independentista, fue con la consolidación del gobierno conservador en la década de 1840 cuando se organizó bajo la dirección de la Universidad de Chile fundada junto a la Escuela Normal de Preceptores en 1842.

La fundamentación de los grandes educacionistas y políticos de la época, de Andrés Bello, de Domingo Faustino Sarmiento y de Manuel Montt, fue el ingreso de los sectores populares a la ciudadanía política en que se sostenía la soberanía popular y la identificación del bien del individuo con el bien social. "En países rejidos por instituciones republicanas”, decía Manuel Montt, “en donde todos los miembros son llamados a trabajar en el bien común, i a tomar una parte más o menos importante en los negocios públicos, el primer deber de los encargados de rejirlos, es preparar a los ciudadanos para que llenen sus funciones, ilustrando su inteligencia, i desarrollando en su corazón los principios de moralidad y de virtud. Aun cuando se prescindiera de esa consideración poderosa, bastaría reflexionar que el mayor bien social para el mayor número de individuos, no puede lograrse sin una instrucción primaria competente..."54.

La expansión de la escuela era la contracara del requisito de alfabetismo para votar. De hecho, la ley electoral de 1833 postergó ese requisito por diez años porque la educación no estaba suficientemente esparcida. No era que lo estuviera cuando ese requisito entró en vigencia en la ley electoral de 1842, pero el gobierno ya estaba organizando una política al respecto.

El hito más significativo desde la perspectiva del pensamiento liberal del período fue el proyecto que presentó Manuel Montt como diputado en el Congreso en 1849, en una coyuntura política compleja.

\footnotetext{
${ }^{54}$ Manuel Montt, Moción presentada al Congreso Nacional por el Señor Diputado D. Manuel Montt sobre Instrucción Primaria, 1849, p. 3.
} 
Los dos artículos que presidieron el proyecto anticipaban algunos de los grandes debates del liberalismo que perduran hasta el presente. El primero fue definir la educación como un derecho. Su justificación hablaba por sí misma: "En el primer artículo se reconoce el derecho que todos los habitantes del Estado tienen a que se les dé la instrucción primaria indispensable para el ejercicio de los derechos y el cumplimiento de los deberes, que como hombres y como individuos de una sociedad les corresponde. El derecho a una educación competente reposa en los mismos fundamentos que el que tiene el ciudadano para que se le proteja su persona y su propiedad, para que se le administre justicia en sus contiendas, para que le asegure la libre publicación de sus pensamientos..."

La Cámara, sin embargo, no estuvo de acuerdo con él. Algunos consideraron que aquel derecho ya estaba en la Constitución, una interpretación que ignoraba la verdadera novedad de la ley. Quien sí la comprendió aunque con temor fue el diputado Antonio Varas, el más estrecho colaborador político de Montt. "El artículo en cuestión tiene en mi concepto cierto sabor a socialismo", sostuvo, pues significaba aceptar, por ejemplo, que se le exigiera al Estado el alimento necesario para la subsistencia y "que los asociados teniendo derecho de exigirlo todo a la asociación, hoy podrían pedir instrucción, mañana alimento, después vestido, hasta caer en todas las consecuencias de aquel princi-

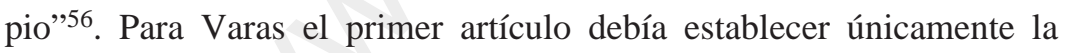
dirección del Estado de la instrucción primaria y así quedó.

Montt tuvo más éxito en su segunda novedad, que explicitaba el derecho a la educación de hombres y de mujeres. "Ambos sexos merecen igual atención”; privar de ese derecho a la mitad de la población era una injusticia. Ello demuestra que Montt concebía ese derecho no sólo como político sino también como civil y fue la primera vez en la historia legislativa del liberalismo chileno que la mujer apareció como tal en la definición de un derecho. Así lo estableció la ley de instrucción primaria de 1860 cuya importancia residió en establecer la gratuidad y la proporción de población por escuela ${ }^{57}$.

${ }^{55}$ Manuel Montt, Moción presentada al Congreso Nacional por el Señor Diputado D. Manuel Montt sobre Instrucción Primaria, 1849, p. 8.

${ }^{56}$ SCN, Diputados, sesión del 7 de junio 1859, p. 15.

${ }^{57} \mathrm{Sin}$ embargo, el liberalismo chileno se encontraba a la zaga del sector conservador en lo que respecta tanto a la educación como al sufragio femenino. Sol Serrano, 


\section{La libertad de asociación}

Hasta fines de la década de 1860 la libertad de asociación era una bandera de los sectores liberales avanzados, pues era una garantía que no tenía estatuto constitucional. Por ello, fue incorporada en las reformas constitucionales de la década de $1870^{58}$. En el momento en que el diputado liberal Jorge Huneeus la propuso, con uniformidad y consistencia planificada, vino la embestida conservadora que cambió enteramente el giro del debate. Abdón Cifuentes propuso una indicación para que se reconociera el derecho de asociación sin autorización previa, pero agregó un punto clave: que las sociedades que no fueran civiles o comerciales fueran reconocidas como personas jurídicas con el solo requisito de comunicarlo al Presidente de la República. El objetivo no pasó inadvertido para nadie ${ }^{59}$.

Los conservadores estaban proponiendo que las sociedades no comerciales pudieran tener personalidad jurídica, y por tanto derecho a heredar y a adquirir bienes, sin depender de la autorización del Presidente de la República que las otorgaba en conjunto con el Consejo de Estado. Consideraban ese derecho constitutivo de la libertad individual, pues sin los derechos civiles los derechos políticos perdían su razón de ser. "Sin garantías para su persona y propiedad, el derecho de concurrir a las plazas públicas para elegir mandatario o gobernantes, sería únicamente el derecho a escoger a sus propios verdugos, a los señores de sus vidas y hacienda"60. Con ello no sólo querían evitar futuras hostilidades del Estado hacia las congregaciones y sociedades católicas, sino también enmendar las exigencias que el Código Civil imponía a la adquisición de bienes por parte de las corporaciones, como la prohibición de mantenerlos indefinidamente, y solicitar periódicamente su retención al Congreso.

Miguel Luis Amunátegui, el principal contrincante liberal en esta polémica, entró al problema de fondo. La Iglesia quería un tipo de

\footnotetext{
"El Poder de la Obediencia: Religiosas Modernas en la Sociedad Chilena del Siglo XIX", 2004, pp. 295-313. Érika Maza Valenzuela, "Liberales, Radicales y la Ciudadanía de la Mujer en Chile, 1872-1930”, pp. 319-356.

${ }^{58}$ Cristián Gazmuri, El “48” Chileno. Igualitarios, Reformistas, Radicales, Masones y Bomberos, 1992, p. 103.

${ }^{59}$ SCN, Diputados, 15 de septiembre de 1873, p. 544.

${ }^{60}$ SCN, Diputados, 29 de septiembre de 1873, p. 544.
} 
personalidad jurídica sin vigilancia de la autoridad civil; volver al régimen de "manos muertas" y a la acumulación de las propiedades territoriales que contravenía los principios económicos que la legislación presente trataba de favorecer. Por último, sostuvo que muchas de sociedades católicas coartaban la libertad personal al obligar a sus miembros a los votos perpetuos, a las abstinencias y a las mortificaciones. Eran sociedades, en definitiva, peligrosas para la organización de la propiedad territorial y para la libertad personal.

Los conservadores no sólo defendieron las antiguas asociaciones religiosas. Defendieron el asociacionismo como el espacio público de la democracia, colaborador del Estado, a la vez que freno de su posible arbitrariedad. Por eso la libertad de asociación era la más expuesta a ser víctima del poder público. Cifuentes gustaba polemizar con los liberales en su propio lenguaje: le tenían miedo a la libertad, eran curadores de un país impúber, llevaban al país al tutelaje colonial donde todo requería el paternal permiso del tutor omnipotente. Era inconcebible, sostenía, que en un régimen republicano hubiera tutela y censura previa a la libertad de asociación defendida por unos liberales que estaban dispuestos a coartar una libertad por miedo de su abuso. Finalmente llegó al fondo de su argumento recurriendo a la teoría populista española y dándole carácter democrático: "Los partidarios de la teoría pagana (de gobierno) quieren que la libertad del ciudadano quede sujeta a la tutela y al capricho del Gobierno. Los partidarios de la teoría cristiana, que es la teoría liberal, queremos abolir la tutela, dejar al ciudadano el libre uso de sus derechos y sujetar a responsabilidad sus abusos, justamente porque lo declaramos libre"61. En definitiva, denunciaba que los liberales defendían la libertad mientras no fuera la de los católicos.

Joaquín Blest Gana razonaba que para Cifuentes todas las disposiciones civiles eran una invasión arbitraria en los sagrados límites del derecho natural; como si existiese una libertad natural perfecta en algún idílico lugar. "No, no es ésa la libertad que pretendemos los liberales”, contestaba Blest Gana, cobrándoles a los conservadores todos aquellos puntos en que habían defendido el exclusivismo católico y oponiendo a ese concepto de libertad, el de igualdad en el derecho: "Nos contentamos con una mucha más modesta, pero también más positiva; queremos la libertad que no viole el derecho ajeno ni sea perjudicial a la

${ }^{61}$ SCN, Diputados, 6 de octubre de 1873, pp. 17-23. 
sociedad. Queremos por ejemplo la libertad de conciencia manifestada por medio del ejercicio de todos los cultos que la convicción quiera tributar a Dios; queremos que bajo la protección de la ley, el hombre tenga el derecho de constituir una familia cualquiera que sea su creencia; queremos que los hijos tengan el derecho de pedir un rincón de tierra al lado de sus padres sin que hayan muros ni cercas de árboles que separen a los que estuvieron unidos en vida; queremos que la ley niveladora del derecho no reconozca la distinción de clases privilegiadas, que pretenden derivar de la ley divina, una excepción inconciliable con la igualdad humana"62.

Enrique Tocornal, diputado conservador y jurisconsulto, (se enfrentaron aquí los principales expertos en derecho civil de su tiempo) sostenía que el Código Civil sólo exigía a las corporaciones de beneficencia pública, gremios y cofradías, permiso al Presidente de la República para constituirse y al Congreso para mantener sus bienes. Podía establecerse libremente una sociedad para hablar de política, de música o de canto, o comprar un sitio para hacer cancha de carreras, pero no para la beneficencia. Negó que estuviera defendiendo las manos muertas, las vinculaciones, la distinción de clases. Sólo pedían, según su argumento, la igualdad ante la ley: que las corporaciones de beneficencia tuvieran el mismo estatuto legal que las sociedades comerciales. De paso dejó entrever la diferencia de valores y de estilos de vida que representaban estas diferentes sociabilidades. Dijo que el Club de la Unión tenía más derechos que los talleres de la Sociedad San Vicente de Paul, porque uno se apoyaba en los fuertes y poderosos y el otro en los débiles, enfermos y moribundos.

Esa indicación finalmente se perdió, mientras que se aprobó por unanimidad el derecho de asociarse sin permiso previo como garantía constitucional. Ello indica que la discusión sobre la libertad de asociación debe comprenderse desde las prácticas asociativas liberales que reclamaban libertad ante un Estado que las censuraba y restringía con sus poderes coercitivos legalmente establecidos como el estado de sitio, así como desde las asociaciones católicas y su transformación ante la secularización del Estado ${ }^{63}$.

62 Ibid.

${ }^{63}$ Sol Serrrano, "La Definición de lo Público en un Estado Católico”, 1999, pp. 211-232. 
La primera ola de secularización obligó al catolicismo a reciclar una vida asociativa que era mucho más fuerte en el siglo XIX de lo que la historiografía ha señalado y a crear medios para luchar en nuevos escenarios: "La tribuna, los comicios populares, la prensa, la asociación, esas máquinas de guerra con que se alcanza el imperio de la opinión en las sociedades modernas", como lo describía Abdón Cifuentes. De hecho, el primer partido político en constituirse fue el Conservador y gatilló la formación de los otros partidos. Fue también el primero en estructurarse y organizar una conferencia nacional en 1878 con la presencia de 38 delegaciones de todo el país. Con ello queremos resaltar que el recorrido del liberalismo en el siglo XIX chileno tuvo acompañantes inesperados. La libertad de asociación fue efectivamente incorporada a las garantías constitucionales, lo cual contribuyó fuertemente a la institucionalización de los partidos políticos. Así, la libertad de asociación fue una de las facetas del liberalismo decimonónico que reunió la gobernabilidad con la expansión de las libertades.

\section{La ampliación electoral}

El problema de la representación definió buena parte de la formación del sistema político chileno. El Congreso que convocó la primera Junta de Gobierno estableció un reglamento electoral que introdujo el principio de la representación territorial y proporcional, y con ello el concepto de electores individuos ${ }^{64}$. Los elegidos tenían requisitos propios de las elecciones tradicionales como "virtudes patrióticas", "talento", "prudencia”, “de buena opinión y fama”, que las Constituciones posteriores abandonaron por categorías más concretas. Sin embargo, ampliaba la convocatoria de electores cuyas listas las confeccionaban no sólo los cabildos sino la autoridad local y el cura párroco. La Constitución de 1828 definió como requisitos para ser elector la nacionalidad, edad según estado civil y propiedad o empleo y no consideró el alfabetismo, como lo habían hecho algunas leyes anteriores. La Constitución de 1833 reintrodujo la restricción del alfabetismo que la ley de elecciones, como se mencionó, postergó por diez años. Este fue el

64 “Convocación al Congreso Nacional de 1811 por la Junta de Gobierno, 15 de diciembre de 1818”, en Sesiones de los Cuerpos Legislativos de la República de Chile. 1811 a 1845 (publicación posteriormente denominada Sesiones del Congreso Nacional [SCN]), 1887, T. I, pp. 9-11. 
cuerpo electoral hasta la ampliación del sufragio en 1874 que eliminó el requisito de propiedad. Las elecciones se realizaron a lo largo del siglo con extraordinaria regularidad ${ }^{65}$.

La ampliación electoral en este período, sin embargo, no debe juzgarse por el aumento del electorado a través de la supresión de restricciones, pues la población que podía votar era considerablemente mayor que los inscritos y que los votantes. Según el Censo Electoral en 1871 un 2,2\% de la población estaba calificada y votó efectivamente el 1,5\% ${ }^{66}$. La ampliación, más bien, hay que analizarla desde la perspectiva de las posibilidades de competencia y, por tanto, en los procedimientos para calificar a dicho cuerpo electoral, fuertemente dominados por el Ejecutivo. La calificación constituyó uno de los principales debates de las reformas electorales impulsadas por los sectores liberales que impugnaban los poderes del gobierno. Las elecciones, de acuerdo con la ley de 1833, estaban a cargo del gobernador que abría los registros para la inscripción y de una Junta Electoral nombrada por el Consejo Municipal entre los vecinos inscritos escogidos al azar. Dicha Junta establecía la lista de calificados a quienes se les entregaba una papeleta que debían presentar al momento de la elección. La Junta también estaba encargada del conteo de los votos. Las distintas etapas del proceso permitían mucho control por parte de las autoridades públicas. Sin embargo, al contrario de lo que suele señalar la historiografía política chilena, las elecciones estuvieron lejos de ser sólo un fraude manipulado por el cohecho y por la intervención coercitiva de las autoridades locales. Aquello se daba dentro de un complejo proceso institucional donde la competencia entre líderes locales o políticos nacionales consistía en fiscalizar las distintas instancias para luego poder impugnarlas ante el Consejo de Estado y el Congreso Nacional. Allí, denunciaban fraudes ya fuera en la calificación o en la manipulación del voto como cuando se anotaban los nombres de candidatos en las papeletas antes de que fueran depositadas en las urnas. Ello obligaba a las instituciones correspondientes a revisar los procesos, revisiones que daban motivo de acusaciones en la prensa y en el Congreso. Los aspirantes que no eran favoreci-

${ }^{65}$ Véanse las fuentes citadas de J. Samuel Valenzuela en la nota $\mathrm{N}^{\circ} 6$.

${ }^{66}$ Anuario Estadístico de la República de Chile, correspondiente a los años 1870 i 1871, 1871, p. 606. 
dos por las listas del gobierno, trataban de concentrar el voto en un candidato para dificultar el fraude.

Las reformas electorales apuntaron a ampliar las posibilidades de competencia. La ley electoral de 1869 estableció registros trienales y no para cada elección, excluyó a la autoridad central de la localidad, intendente, gobernador o subdelegado, de las Juntas Electorales que ahora debían ser elegidos por el municipio entre los primeros cuarenta contribuyentes de la localidad. La reforma electoral de 1874 fue mucho más lejos, al sacar a los municipios del proceso de nombramiento de las Juntas Electorales y depositarlo en los mayores contribuyentes ${ }^{67}$. Se estableció el voto acumulativo para las elecciones de diputados y eliminó el requisito de propiedad o empleo al suponer que todo alfabeto lo cumplía. El cuerpo electoral efectivamente aumentó y en 1879 los inscritos eran un 6,9\% de la población y un 4,8\% efectivamente votó $^{68}$. Es difícil establecer una relación causal directa, pero las reformas en la calificación también incidieron en la ampliación del cuerpo electoral.

La mayor competencia electoral, y por ende la ampliación del electorado, se vio favorecida por la reducción del período presidencial a sólo uno de cinco años. Como lo manifestó la Comisión pertinente del Senado en 1872: "La historia de los últimos cuarenta años nos ha demostrado que en realidad el período presidencial dura diez años. Tan largo período tiene gravísimos inconvenientes, no sólo porque debilita el carácter alternativo de nuestra forma de gobierno, sino porque se imposibilita por muy dilatado tiempo el triunfo de ideas que, elaboradas convenientemente en los combates de la opinión, pueden consultar mejor las conveniencias del país que las que diez años antes predominaron encarnadas en la persona del Jefe Supremo"69. La ley fue aprobada por el Congreso en 1872. Igual inspiración se encuentra en la reducción del período de los senadores, de nueve a seis años, por votación directa, en 1874.

El liberalismo del siglo XIX, que para estos efectos comprende también a los conservadores ultramontanos, construyó un sistema político ideológicamente plural en base a una representación restringida

${ }^{67}$ Ricardo Donoso, Las Ideas Políticas en Chile, 1946, p. 422.

68 “Censo Electoral 1878-1879”,en Anuario Estadístico de la República de Chile, correspondiente a los años 1877 i 1878, 1879, p. 312.

${ }^{69}$ Citado por Donoso, Las Ideas Políticas en Chile, 1946, p. 420. 
(como lo era, incluso más, en Europa y en Estados Unidos), que institucionalizó formas de competencia más frecuentes, aunque todavía no libres de intervención gubernamental ${ }^{70}$.

\section{Conclusión}

El liberalismo chileno no siguió una cronología ascendente y triunfal, ni fue esencialmente opuesto a un bando supuestamente "conservador”. Si bien existieron grupos, partidos o movimientos políticos que llevaron esas rúbricas, los valores y conceptos políticos gravitaban cada vez más fuertemente en torno a un liberalismo clásico y compartido, antes que sectariamente partidista. Los supuestos contendientes utilizaron el lenguaje de la libertad y los derechos individuales y buscaron un equilibrio entre los componentes del gobierno representativo.

Lo que fue peculiar al liberalismo chileno, sobre todo en comparación con otros casos hispanoamericanos, es la ausencia de radicalismo y su énfasis en la reforma. Esto no quiere decir que la secularización de la sociedad no fuese drástica, o que no generara fuertes tensiones políticas, sino que las transformaciones fueron realizadas vía reforma, no revoluciones, o nuevos experimentos constitucionales más allá de 1833. También fue notable el énfasis en contener al Ejecutivo a través del Congreso, lo que comenzó a sentirse ya en el gobierno de Bulnes, y que culminó con la Revolución de 1891.

Esta última demuestra, sin embargo, que existía una tradición política chilena a la que el liberalismo no logró sobreponerse. Ya sea bajo el gobierno de O’Higgins, Prieto con Portales, Manuel Montt, o Balmaceda en el siglo XIX, o Ibáñez y Pinochet en el siglo XX, el Ejecutivo ha buscado predominar, $\mathrm{y}$ frecuentemente lo ha logrado, imponiéndose sobre el Congreso y suspendiéndolo cuando así lo han dictado sus intereses políticos. Esta relación tensa y a veces violenta entre dos componentes fundamentales del gobierno representativo ilustra el eje sobre el que ha girado la política chilena, y que está también en la base del pensamiento liberal: el equilibrio necesario, en situaciones cambiantes, entre el orden y la libertad.

${ }^{70} \mathrm{El}$ acceso al sufragio en Chile era legalmente más amplio que en Europa antes de 1848, puesto que podían votar los artesanos y empleados con sueldo y domicilio. En relación a Estados Unidos, Chile no tenía esclavitud y la población negra tenía los mismos derechos electorales que el resto de la población. Agradecemos a Samuel Valenzuela esta observación. 


\section{BiBLIOGRAFÍA}

Anales de la Universidad de Chile. Varios tomos.

Anuario Estadístico de la República de Chile. Varios tomos.

Avila Martel, Alamiro, Antonia Rebolledo, Luz María Fuchslocher et al.: Estudios sobre José Victorino Lastarria. Santiago: Ediciones de la Universidad de Chile, 1988.

Bello, Andrés: Labor en el Senado de Chile (Discursos y Escritos), tomo XX. Caracas: Fundación la Casa de Bello, 1981.

Boletín Eclesiástico: Varios tomos.

Brahm García, Enrique: Tendencias Críticas en el Conservantismo después de Portales. Santiago: Instituto de Estudios Generales, Serie Estudios Históricos, 1992.

Briseño, Ramón: Estadística Bibliográfica de la Literatura Chilena, 1812-1879. Santiago: Imprenta Chilena, 1962.

Cifuentes, Abdón: Memorias. Santiago: Editorial Nascimento, 1936.

Concha y Toro, Melchor: Chile Durante los Años de 1824 a 1828. Santiago: Imprenta Nacional, 1862.

Collier, Simon: Ideas and Politics of Chilean Independence, 1808-1833. Cambridge: Cambridge University Press, 1967.

"The Historiography of the 'Portalian' Period (1830-1891) in Chile”. Hispanic American Historical Review, 57, № 4 (1977).

"From Independence to the War of the Pacific". En Leslie Bethell (ed.), Chile since Independence. Cambridge: Cambridge University Press, 1993.

Chile: La Construcción de una República, 1830-1865. Política e Ideas. Trad. Fernando Purcell. Santiago: Ediciones Universidad Católica de Chile, 2005.

Cristi, Renato y Pablo Ruiz-Tagle: La República de Chile: Teoría y Práctica del Constitucionalismo Republicano. Santiago: Ediciones LOM, 2006.

Donoso, Ricardo: Las Ideas Políticas en Chile. México: Fondo de Cultura Económica, 1946.

Edwards, Agustín: Cuatro Presidentes de Chile. Valparaíso: Sociedad Imprenta y Litografía Universo, 1932.

Edwards, Alberto: El Gobierno de don Manuel Montt, 1851-1861. Santiago: Editorial Nascimento, 1932.

Errázuriz, Isidoro: Historia de la Administración Errázuriz. Valparaíso: Imprenta de la Patria, 1877.

Eyzaguirre, Jaime: Historia de las Instituciones Políticas y Sociales de Chile. Santiago: Editorial Universitaria, 1970.

Fariña Vicuña, Carmen (comp.): Epistolario de Diego Portales, 2 tomos. Santiago: Ediciones Universidad Diego Portales, 2007.

Fuenzalida Grandón, Alejandro: Lastarria i su Tiempo. Santiago: Imprenta Cervantes, 1893.

Gazmuri, Cristián: El “48” Chileno. Igualitarios, Reformistas, Radicales, Masones y Bomberos. Santiago: Editorial Universitaria, 1992.

Heise González, Julio: Historia de Chile. El Período Parlamentario, 1861-1925. Santiago: Editorial Andrés Bello, 1974.

Años de Formación y Aprendizaje Político, 1810-1833. Santiago: Editorial Universitaria, 1978. 
150 Años de Evolución Institucional. Santiago: Andrés Bello, 2007.

Huneeus Gana, Antonio: La Constitución de 1833: Ensayo sobre nuestra Historia Constitucional de un Siglo. Santiago: Editorial Splendid, 1933.

Jaksic, Iván: Academic Rebels in Chile: The Role of Philosophy in Higher Education and

Politics. Albany: State University of New York Press, 1989.

“Sarmiento y la Prensa Chilena, 1841-1851”. Historia, 26 (1991-92).

- Andrés Bello: La Pasión por el Orden. Santiago: Editorial Universitaria, tercera edición, 2010.

Jocelyn-Holt, Alfredo: "Liberalismo y Modernidad. Ideología y Simbolismo en el Chile Decimonónico: Un Marco Teórico”. En Ricardo Krebs y Cristián Gazmuri (eds.), La Revolución Francesa y Chile. Santiago: Editorial Universitaria, 1990.

- La Independencia de Chile: Modernización, Tradición y Mito. Madrid: Editorial MAPFRE, 1992.

Krebs, Ricardo (ed.): Catolicismo y Laicismo. Las Bases Doctrinarias del Conflicto entre la Iglesia y el Estado en Chile. Santiago: Editorial Nueva Universidad, 1981.

Lastarria, José Victorino: Recuerdos Literarios: Datos para la Historia Literaria de la América Española i del Progreso Intelectual de Chile. Santiago: Librería de M. Servat, 1885. Diario Político, 1849-1852. Santiago: Editorial Andrés Bello, 1968.

Lastarria, José Victorino y Federico Errázuriz: Bases de la Reforma. Santiago: Imprenta del Progreso, 1850.

Letelier, Valentín: La Lucha por la Cultura: Miscelánea de Artículos Políticos i Estudios Pedagójicos. Santiago: Imprenta i Encuadernación Barcelona, 1895.

Loveman, Brian: The Constitution of Tyranny: Regimes of Exception in Spanish America. Pittsburgh y Londres: University of Pittsburgh Press, 1993.

Maza Valenzuela, Érika: “Liberales. Radicales y la Ciudadanía de la Mujer en Chile, 18721930”. Estudios Públicos, 69 (verano 1998).

Medina, José Toribio: Biblioteca Chilena de Traductores (1820-1924), segunda edición, corregida y aumentada, con estudio preliminar de Gertrudis Payàs. Santiago: Centro de Investigaciones Diego Barros Arana, 2007.

“Memoria del ministro de Justicia, Culto e Instrucción Pública”. En Anales de la Universidad de Chile, Tomo 40, 1872.

Montt, Manuel: Moción presentada al Congreso Nacional por el señor Diputado D. Manuel Montt sobre Instrucción Primaria. Santiago: Imprenta del Progreso, 1849.

Ossa Santa Cruz, Juan Luis: “El Estado y los Particulares en la Educación Chilena, 18881920”. Estudios Públicos, 106 (otoño 2007).

Pinto Vallejos, Julio y Verónica Valdivia Ortíz de Zárate: ¿Chilenos Todos? La Construcción Social de la Nación (1810-1840). Santiago: Lom Ediciones, 2009.

Piwonka Figueroa, Gonzalo: Orígenes de la Libertad de Prensa en Chile, 1823-1830. Santiago: RIL Editores, 2000.

Rivacoba y Rivacoba, Manuel de: Código Penal de la República de Chile y Actas de las Sesiones de la Comisión Redactora. Valparaíso: EDEVAL, 1974.

Santa Cruz, Lucía (ed.): Liberalismo y Conservantismo en Chile. Santiago: Universidad Adolfo Ibáñez, 2002. 
Salazar, Gabriel: Construcción de Estado en Chile (1800-1837). Democracia de los "Pueblos”. Militarismo Ciudadano. Golpismo Oligárquico. Santiago: Editorial Sudamericana, 2005.

Scully, Timothy R.: Los Partidos Políticos de Centro y la Evolución Política Chilena. Santiago: CIEPLAN-Notre Dame, 1992.

Sesiones del Congreso Nacional (SCN) (inicialmente denominado Sesiones de los Cuerpos Legislativos de la República de Chile). Santiago: Imprenta Nacional, 1875. Varios tomos.

Serrano, Sol: "La Definición de lo Público en un Estado Católico”. Estudios Públicos, 76 (primavera 1999).

"El Poder de la Obediencia: Religiosas Modernas en la Sociedad Chilena del Siglo XIX”. En Pilar Gonzalbo y Berta Ares (eds.), Las Mujeres en la Construcción de las Sociedades Iberoamericanas. Sevilla y México: Consejo Superior de Investigaciones Científicas y El Colegio de México, 2004.

¿ ¿Qué Hacer con Dios en la República? Política y Secularización en Chile, 1845-1885. Santiago: Fondo de Cultura Económica, 2008.

Silva Castro, Raúl: Prensa y Periodismo en Chile, 1812-1956. Santiago: Ediciones de la Universidad de Chile, 1958.

Stuven, Ana María: Las Elites y la Construcción de Chile en las Polémicas Culturales y Políticas del Siglo XIX. Santiago: Ediciones Universidad Católica de Chile, 2000.

Subercaseaux, Bernardo: Cultura y Sociedad Liberal en el Siglo XIX (Lastarria, Ideología y Literatura). Santiago: Editorial Aconcagua, 1981.

Historia del Libro en Chile (Alma y Cuerpo). Santiago: LOM Ediciones, 2000.

Urzúa Valenzuela, Germán: Historia Política de Chile y su Evolución Electoral (Desde 1810 a 1992). Santiago: Editorial Jurídica de Chile, 1992.

Valencia Avaria, Luis: Anales de la República de Chile. Santiago: Editorial Andrés Bello, 1986.

Valenzuela, J. Samuel: Democratización Vía Reforma: La Expansión del Sufragio en Chile. Buenos Aires: Ediciones del IDES, 1985.

"Building Aspects of Democracy: Electoral Practices in Nineteenth-Century Chile”. En Eduardo Posada-Carbó (ed.), Elections Before Democracy: The History of Elections in Europe and Latin America. Londres: Institute of Latin American Studies, 1996.

"La Ley Electoral de 1890 y la Democratización del Régimen Político Chileno”. Estudios Públicos, 71 (invierno 1998).

“From Town Assemblies”. Universidad de Notre Dame, 2009.

Valenzuela, J. Samuel y Érika Maza Valenzuela: “The Politics of Religion in a Catholic Country: Republican Democracy, Social Cristianismo, and the Conservative Party in Chile, 1850-1925”. En Austin Ivereigh (ed.), The Politics of Religion in an Age of Revival. Londres: Institute of Latin American Studies, 2000.

Velasco, Fanor: La Idea Liberal y la Idea Ultramontana. Valparaíso: Imprenta de la Patria, 1871.

Vicuña Mackenna, Benjamín: Historia de la Jornada del 20 de Abril de 1851. Una Batalla en las Calles de Santiago. Santiago: Rafael Jover, Ed., 1878.

- Los Girondinos Chilenos. Prólogo de Cristián Gazmuri. Santiago: Editorial Universitaria, 1989.

Vicuña, Manuel: Un Juez en los Infiernos: Benjamín Vicuña Mackenna. Santiago: Ediciones Universidad Diego Portales, 2009. 